\title{
Peritonitis as the first presentation of systemic lupus erythematous: a case report
}

\author{
Zahedin Kheyri ${ }^{1,2}$, Amirreza Laripour ${ }^{3}$ and Moein Ala ${ }^{4^{*}}$ (D)
}

\begin{abstract}
Background: Systemic lupus erythematosus is an inflammatory disease affecting several organs. Serositis is one of the systemic lupus erythematosus presentations, but peritonitis is a relatively rare presentation. Particularly, it is extremely rare to observe peritonitis as the first presentation of systemic lupus erythematosus.

Case presentation: Here, we present a case of peritonitis without other symptoms of systemic lupus erythematosus, in a patient who was finally diagnosed with systemic lupus erythematosus. Our patient was a 27-year-old Persian/ Caucasian male with fatigue, weakness, weight loss, abdominal distension, massive ascites, and normocytic hemolytic anemia. He did not mention any prior medical conditions and did not use any drugs. There were no signs of thyroid dysfunction, cardiac dysfunction, cancers, infectious diseases, hepatitis, kidney diseases, or other diseases. Low-gradient, high-protein ascites fluid, and positive antinuclear antibody and anti-double stranded DNA were in favor of systemic lupus erythematosus. Corticosteroid pulse therapy led to resolution of ascites, and the patient was discharged with prednisolone and hydroxychloroquine.
\end{abstract}

Conclusion: Peritonitis is a rare presentation of systemic lupus erythematosus, particularly as the first presentation and in the absence of other signs and symptoms; however, systemic lupus erythematosus should be considered as one the differential diagnoses for peritonitis when other etiologies have been ruled out.

Keywords: Systemic lupus erythematous, Peritonitis, Ascites, Low-gradient high-protein ascites fluid, Case-report

\section{Background}

Systemic lupus erythematosus (SLE) is a chronic, multiorgan inflammatory disease that involves the joints, skin, cardiovascular system, lungs, central nervous system, and kidneys [1]. SLE peritonitis is one of the rarest manifestations of SLE, and presents as painless ascites, concurrent with other known symptoms of SLE [2, 3]. The occurrence of SLE ascites is typically associated with nephrotic syndrome, protein-losing enteropathy, and constrictive pericarditis. The occurrence of ascites and peritonitis as primary manifestations of SLE is extremely rare [4].

*Correspondence: moinala75@yahoo.com

${ }^{4}$ School of Medicine, Tehran University of Medical Sciences (TUMS), Tehran, Iran

Full list of author information is available at the end of the article
In this case report, we present a young man with ascites and lupus peritonitis as the first manifestations of SLE.

\section{Case presentation}

The patient was a 27-year-old Persian/Caucasian man with no medical history, who experienced 2 months of abdominal distension and weakness, with concurrent $10 \mathrm{~kg}$ unintentional weight loss. He did not mention nausea, vomiting, dysphagia, diarrhoea, cough, dyspnea, night sweats, or chills. He had no gastrointestinal complaints except feeling fullness. The patient was normoglycemic and had no history of hepatitis, jaundice, diabetes, drug abuse, or alcohol use. On presentation, his blood pressure was $120 / 80 \mathrm{mmHg}$ and his body temperature was $37{ }^{\circ} \mathrm{C}$. Abdominal ascites was apparent, with no icterus or edema. There were no signs of cheilosis, glossitis, lymphadenopathy, or original author(s) and the source, provide a link to the Creative Commons licence, and indicate if changes were made. The images or other third party material in this article are included in the article's Creative Commons licence, unless indicated otherwise in a credit line to the material. If material is not included in the article's Creative Commons licence and your intended use is not permitted by statutory regulation or exceeds the permitted use, you will need to obtain permission directly from the copyright holder. To view a copy of this licence, visit http://creativecommons.org/licenses/by/4.0/. The Creative Commons Public Domain Dedication waiver (http://creativeco mmons.org/publicdomain/zero/1.0/) applies to the data made available in this article, unless otherwise stated in a credit line to the data. 
organomegaly on physical examination. Serological tests for viral hepatitis and human immunodeficiency virus (HIV) were negative.

Laboratory findings are presented in Table 1.

The patients reticulocyte production index was more than 2.5. The 24-hour urine test detected $250 \mathrm{mg}$ of protein. Color Doppler ultrasonography of abdominal vessels was normal. Abdominal, pelvic, and chest computed tomography (CT) scan showed bilateral pleural effusions and massive ascites. The patient underwent abdominal paracentesis, which revealed a low-gradient, high-protein fluid. Ascites fluid adenosine deaminase (ADA) and QuantiFERON test results were negative. In addition, PCR test was negative for tuberculosis. Furthermore, cytological test showed no evidence of malignancy. No signs of cardiac dysfunction were detected in his echocardiography. In addition, his thyroid function test, upper gastrointestinal endoscopy, and chest X-ray were normal.

Diagnostic laparoscopy and peritoneal biopsy were also negative for malignancy. With the exclusion of other etiologies of ascites, rheumatologic tests were requested. His ANA and anti-dsDNA were reported high. Due to positive antinuclear antibodies (ANA) and anti-dsDNA, as well as low levels of complement $\mathrm{C} 3$ and $\mathrm{C} 4$, the patient was diagnosed with lupus peritonitis. Initially, he was treated with methylprednisolone pulse therapy $(1000 \mathrm{mg} /$ day for three consecutive days) and then with high-dose prednisolone of $60 \mathrm{mg} /$ day, which was finally tapered to $7.5 \mathrm{mg} /$ day. The initial corticosteroid pulse therapy markedly improved ascites, and the patient was discharged with prednisolone and hydroxychloroquine. He was followed-up in the outpatient clinic up to 3 months. His symptoms did not return up to 3 months. He was not accessible after 3 months of follow-up.

Table 1 Laboratory findings at admission

\begin{tabular}{|c|c|c|c|}
\hline Variable & Result & Variable & Result \\
\hline White blood cell count (WBC) & $\begin{array}{l}10,800 / \mu \mathrm{L} \\
(4500<\mathrm{NL}<11,000)\end{array}$ & Aspartate transaminase (AST) & $\begin{array}{l}14 \mathrm{IU} / \mathrm{L} \\
(\mathrm{NL}<40)\end{array}$ \\
\hline Neutrophil & $74 \%$ & Alanine transaminase (ALT) & $\begin{array}{l}10 \mathrm{IU} / \mathrm{L} \\
(\mathrm{NL}<40)\end{array}$ \\
\hline Lymphocyte & $22 \%$ & Alkaline phosphatase (ALP) & $\begin{array}{l}102 \mathrm{IU} / \mathrm{L} \\
(\mathrm{NL}<147)\end{array}$ \\
\hline Hemoglobin & $8.5 \mathrm{~g} / \mathrm{dL}(14<\mathrm{NL}<18)$ & Total bilirubin & $0.7 \mathrm{mg} / \mathrm{dL}(\mathrm{NL}<1.2)$ \\
\hline Mean corpuscular volume (MCV) & $85 \mathrm{fL}(80<\mathrm{NL}<100)$ & Blood urea nitrogen (BUN) & $16 \mathrm{mg} / \mathrm{dL}(6<\mathrm{NL}<24)$ \\
\hline Platelet count & $\begin{array}{l}301,000 / \mu \mathrm{L} \\
(150,000<\mathrm{NL}<450,000)\end{array}$ & Creatinine & $0.7 \mathrm{mg} / \mathrm{dL}(\mathrm{NL}<1.2)$ \\
\hline Albumin & $\begin{array}{l}4 \mathrm{~g} / \mathrm{dL} \\
(3.5<\mathrm{NL}<5.4)\end{array}$ & Total protein & $8 \mathrm{~g} / \mathrm{dL}(6<\mathrm{NL}<8.3)$ \\
\hline
\end{tabular}

\section{Discussion}

SLE is an autoimmune, multiorgan disease [5]. One of the American College of Rheumatology diagnostic criteria for SLE is pleural and pericardial inflammation, which is nonspecific but prevalent $[6,7]$. Serous membrane inflammation involving the pericardium, pleura, and peritoneum can cause pain, fluid accumulation, adhesions, and even fibrosis [2]. A European study with a 10-year analysis of 1000 patients with SLE follow-up found that serositis occurred in nearly 16\%; however, peritoneal involvement was extremely rare [8].

In an autopsy study of patients with SLE, $60-70 \%$ had peritoneal involvement, whereas only $10 \%$ showed clinical manifestations throughout their lives [9]. Ascites in SLE is rarely massive; it is often painless, has a gradual onset, and is rarely reported as the first manifestation of SLE, usually following other symptoms. In addition, ascites can be a result of nephrotic syndrome, proteinlosing enteropathy, or constrictive pericarditis [10]. However, ascites appeared as the first presentation of SLE in our patient.

The first step in ascites treatment is the correct diagnosis of its etiology. Portal hypertension and peritoneal disease can lead to fluid accumulation in the abdominal cavity through activation of the renin-angiotensin-aldosterone system, sodium and water retention, increased plasma volume, and fluid secretion into the serosa-lined cavity [11].

The first step in diagnosing the etiology of ascites is fluid analysis. In portal hypertension, ascites results from vascular hydrostatic pressure, which leads to the formation of transudate fluid. On the other hand, in inflammatory or neoplastic peritoneal disease, changes in the permeability of vascular membranes result in the production of protein-rich exudative fluid [11].

The mechanism of ascites development in lupus peritonitis has not been fully identified; however, there are 
two theories. One is the production of autoantibodies by B-lymphocytes. These autoantibodies precipitate in the peritoneum and cause local inflammatory reactions through binding to antigens and forming immune complexes. Another theory attributes ascites to inflammation of peritoneal vessels or serous membranes surrounding abdominal organs. Due to peritoneal involvement in patients with SLE in both conditions, ascites fluid is exudative [12].

Lupus peritonitis should be considered in the differential diagnosis of patients with exudative ascites after exclusion of other more common causes, including peritoneal carcinomatosis, primary mesothelioma, peritoneal pseudomyxoma, hepatocellular carcinoma, peritoneal tuberculosis, HIV-associated peritonitis, nephrotic syndrome, protein-losing enteropathy, and severe malnutrition [11]. Our patient had massive ascites without typical symptoms of SLE as defined by the American College of Rheumatology. During his workup, there were no findings in favor of other more common etiologies of ascites, and his laboratory findings were suggestive of SLE. Despite previous studies, this rare case of SLE shows that SLE can present with massive ascites as the first presentation. The absence of other clinical findings cannot completely rule out SLE and it should be considered as one of the differential diagnoses.

The prognosis of lupus peritonitis is usually good when appropriate treatment is initiated. The treatment is based on nonsteroidal antiinflammatory drugs (NSAIDs) and corticosteroids. In refractory cases characterized by persistent fluid accumulation in the serosal cavity, immunomodulators or immunosuppressants, particularly pulse therapy with cyclophosphamide, can be used $[2,8$, $10,13]$. Similarly, our patient responded to initial corticosteroid pulse therapy and his ascites volume decreased within a few days.

\section{Conclusion}

Serositis is a common finding in SLE; however, peritoneal involvement is extremely rare, particularly as the first presentation of the disease. SLE peritonitis should be considered in the differential diagnosis of patients with exudative ascites after exclusion of other causes. This rare case of SLE shows that peritonitis can be the first clinical presentation of SLE, and the absence of typical symptoms of SLE cannot rule out the disease. The prognosis of SLE peritonitis is usually good, and treatment is based on NSAIDs and corticosteroids. Immunomodulators and immunosuppressants should be considered for refractory SLE peritonitis.

\section{Acknowledgements}

None.

\section{Authors' contributions}

ZK reported this rare case of SLE. AL wrote the article and MA edited it. All authors read and approved the final manuscript.

Funding

No funds or other kinds of financial support were received for this case report.

Availability of data and materials

Not applicable

\section{Declarations}

\section{Ethics approval and consent to participate}

This case report was written after obtaining patient's informed consent for publication. The patient did not undergo additional diagnostic procedures and therapeutic plans for this case report. This unusual and rare case of SLE was reported after obtaining patient's informed consent. In addition, the ethics committee of Tehran University of Medical Sciences (TUMS) certified this case report (IR.TUMS.MEDICINE.REC.1400.097).

\section{Consent for publication}

Written informed consent was obtained from the patient for publication of this case report and any accompanying images. A copy of the written consent is available for review by the Editor-in-Chief of this journal.

\section{Competing interests}

Authors declare no conflicts of interest.

\section{Author details}

${ }^{1}$ Baharloo Hospital, Tehran University of Medical Sciences (TUMS), Tehran, Iran. ${ }^{2}$ Department of Gastroenterology, Tehran University of Medical Sciences (TUMS), Tehran, Iran. ${ }^{3}$ Students' Research Committee, Arak University of Medical Sciences, Arak, Iran. ${ }^{4}$ School of Medicine, Tehran University of Medical Sciences (TUMS), Tehran, Iran.

Received: 29 April 2021 Accepted: 22 November 2021

Published online: 26 December 2021

\section{References}

1. Fu SM, Deshmukh US, Gaskin F. Pathogenesis of systemic lupus erythematosus revisited 2011: end organ resistance to damage, autoantibody initiation and diversification, and HLA-DR. J Autoimmun. 2011;37(2):104-12.

2. Man B, Mok C. Serositis related to systemic lupus erythematosus: prevalence and outcome. Lupus. 2005;14(10):822-6.

3. Zhao J, Bai W, Zhu P, Zhang X, Liu S, Wu L, et al. Chinese SLE treatment and research group (CSTAR) registry VII: prevalence and clinical significance of serositis in Chinese patients with systemic lupus erythematosus. Lupus. 2016;25(6):652-7.

4. McVorran S, Song J, Pochineni V, Abrudescu-Opran A. Systemic lupus erythematosus presenting with massive ascites: a case of pseudo-pseudo Meigs syndrome. Case Rep Rheumatol. 2016. https://doi.org/10.1155/ 2016/8701763.

5. Rahman A, Isenberg DA. Systemic lupus erythematosus. N Engl J Med. 2008;358(9):929-39.

6. Dahlström Ö, Sjöwall C. The diagnostic accuracies of the 2012 SLICC criteria and the proposed EULAR/ACR criteria for systemic lupus erythematosus classification are comparable. Lupus. 2019;28(6):778-82.

7. Teng J, Ye J, Zhou Z, Lu C, Chi H, Cheng X, et al. A comparison of the performance of the 2019 European League Against Rheumatism/American College of Rheumatology criteria and the 2012 Systemic Lupus International Collaborating Clinics criteria with the 1997 American College of Rheumatology classification criteria for systemic lupus erythematous in new-onset Chinese patients. Lupus. 2020;29(6):617-24.

8. Kaklamanis P, Vayopoulos G, Stamatelos G, Dadinas G, Tsokos G. Chronic lupus peritonitis with ascites. Ann Rheum Dis. 1991;50(3):176-7.

9. Takeno $M$, Ishigatsubo $Y$. Intestinal manifestations in systemic lupus erythematosus. Intern Med. 2006:45(2):41-2. 
10. Weinstein PJ, Noyer CM. Rapid onset of massive ascites as the initial presentation of systemic lupus erythematosus. Am J Gastroenterol. 2000;95(1):302-3.

11. Hou W, Sanyal AJ. Ascites: diagnosis and management. Med Clin. 2009;93(4):801-17.

12. Pott Junior $H$, Amate Neto A, Teixeira MAB, Provenza JR. Ascites due to lupus peritonitis: a rare form of onset of systemic lupus erythematosus. Rev Bras Reumatol. 2012;52(1):116-9.

13. Provenzano G, Rinaldi F, Le Moli S, Pagliaro L. Chronic lupus peritonitis responsive to treatment with cyclophosphamide. Br J Rheumatol. 1993;32(12):1116

\section{Publisher's Note}

Springer Nature remains neutral with regard to jurisdictional claims in published maps and institutional affiliations.

- fast, convenient online submission

- thorough peer review by experienced researchers in your field

- rapid publication on acceptance

- support for research data, including large and complex data types

- gold Open Access which fosters wider collaboration and increased citations

- maximum visibility for your research: over 100M website views per year

At BMC, research is always in progress.

Learn more biomedcentral.com/submissions 